Brit. J. industr. Med., 1951, 8, 22.

\title{
CONTAMINATION OF CETRIMIDE AND OTHER FLUIDS WITH PSEUDOMONAS PYOCYANEA
}

\author{
BY \\ E. J. L. LOWBURY \\ From the Medical Research Council Industrial Medicine Research Unit, Birmingham \\ (RECEIVED FOR PUBLICATION SEPTEMBER 1, 1950)
}

When wounds which can be adequately covered acquire bacterial infection in spite of a strict "no-touch" dressing technique (M.R.C. War Memo. No. 6, 1941 ; Clayton-Cooper and Williams, 1945), the sterility of materials applied during the dressing falls under suspicion. The usual methods of sterilizing gauze, cotton wool, bandages, and surgical instruments are effective if properly carried out, so it is more probable that a fluid or cream applied locally or used for holding sterile instruments might be conveying the infective agent. Soap solution, cetrimide, "dettol" and calamine lotion are commonly dispensed in large corked or stoppered bottles which are sometimes not replaced for many days, and during that time they are frequently opened. Contamination of such bottles is likely, and the survival or multiplication of some coliforms and especially of Pseudomonas pyocyanea is reported to be possible even in solutions of cetrimide (Williams, Clayton-Cooper, Faulkner, and Thomas, 1944).

It is common both in factory surgeries and in hospitals for injuries to be cleansed with soap solution or cetrimide and for Cheattle's forceps to be kept standing in dilute " dettol ". The presence of added infection with $P$ s. pyocyanea in a number of adequately covered wounds prompted the sampling of various fluids and creams.

Isolation of Ps. pyocyanea from Hospital Fluids

Absorbent cotton wool swabs were dipped into bottles of $1 \%$ cetrimide solution, $2 \%$ soap solution, calamine lotion, $10 \%$ " dettol ", penicillin cream, and a number of other fluids used in hospital dressing stations and operating theatres. Samples were taken from bottles which were actually in use, some of them containing only a remnant of fluid.

Swabs were inoculated on plates of a selective medium for Ps. pyocyanea $(0.1 \%$ cetrimide agar; Lowbury, 1951) and in nutrient broth. After 24 hours' incubation at $37^{\circ} \mathrm{C}$. the broth was subcultured to cetrimide agar plates. All plates were examined after 24 hours' and 48 hours' incubation at $37^{\circ} \mathrm{C}$., and Ps. pyocyanea was recognized by detecting green pigment and characteristic fluorescence under an ultra-violet lamp with a dark glass filter.

The results of sampling were as follows :

\begin{tabular}{|c|c|c|}
\hline Fluid & $\begin{array}{l}\text { No. of Bottles } \\
\text { Sampied }\end{array}$ & $\begin{array}{c}\text { Ps. pyocyanea } \\
\text { Present }\end{array}$ \\
\hline 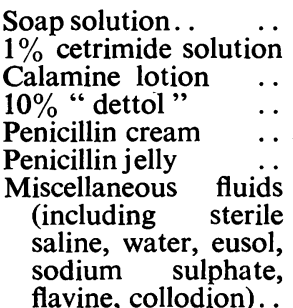 & $\begin{array}{r}18 \\
23 \\
14 \\
9 \\
12 \\
5\end{array}$ & $\begin{array}{r}18 \\
6 \\
10 \\
3 \\
0 \\
0\end{array}$ \\
\hline
\end{tabular}

The bottles from which Ps. pyocyanea was isolated had corks. A separate sampling from the cork and inside of neck and from the cetrimide solution of 19 of the bottles sampled showed a higher proportion of positives from the cork (6/19) than from the cetrimide solution (3/23). Ps. pyocyanea was never isolated from the fluid when it was not also found on the cork. Moreover, in three of the bottles from which the organism was isolated, the load of contamination of the cork appeared to be heavier than that of the fluid.

\section{Replacement of Corked by Sterile Screw-capped Bottles}

It is probable that contamination of these fluids occurred through handling of the bottles rather than by deposition from the air. Moreover, once the organism has been introduced it is likely to remain when the bottle is refilled and might possibly contaminate other materials in the dispensary.

To prevent contamination and maintain sterility of these fluids, it seemed desirable and, perhaps, sufficient to dispense them $(a)$ in small bottles, which would be replaced daily; (b) sterile, or at least in sterile bottles; and $(c)$ with covers which 
would overlap the necks of the bottles and protect them from handling. In practice it was found convenient to use screw-cap bottles of $100 \mathrm{ml}$. to $1,000 \mathrm{ml}$. capacity according to the amount of fluid used in a day. Cetrimide, soap, and "dettol " solutions were autoclaved in bottles at $10 \mathrm{lb}$. pressure for one hour, the caps being lightly screwed on. Calamine lotion was dispensed in sterile screw-cap bottles.

A second sampling of cetrimide, soap solution, and calamine lotion was carried out after all the stopered bottles of these fluids in the hospital had been replaced by clean supplies in screw-cap bottles. The results were as follows :

\begin{tabular}{|c|c|c|}
\hline Fluid & $\begin{array}{l}\text { No. of Bottles } \\
\text { Sampled }\end{array}$ & $\begin{array}{c}\text { Ps. pyocyanea } \\
\text { Present }\end{array}$ \\
\hline $\begin{array}{l}1 \% \text { cetrimide solution } \\
\text { Soap solution } \\
\text { Calamine lotion }\end{array}$ & $\begin{array}{l}17 \\
17 \\
12\end{array}$ & $\begin{array}{l}0 \\
0 \\
0\end{array}$ \\
\hline
\end{tabular}

Incidence of Ps. pyocyanea Infections before and after Issue of Screw-cap Bottles

The issue to all wards and to the operating theatres of cetrimide and soap solutions and of calamine lotion in screw-cap bottles, and the withdrawal of previous stocks of these fluids, was adopted between February and April, 1950. To find whether these changes had any immediate effect on the incidence of Ps. pyocyanea infection in the hospital, comparisons were made of the proportions of positive diagnostic swabs from pus, haematomata, wounds, and other surface lesions (except burns) submitted by surgeons to the clinical laboratory before and after the change in the method of dispensing fluids.

Out of 545 swabs examined between May 1, 1949, and April 30, 1950, $101(18 \cdot 5 \%)$ contained Ps. pyocyanea; an average of 8.3 swabs yielded the organism each month (ranging from 3 to 16). In the three months from May 1, 1950, to July 31, 1950 , three out of $104(2.8 \%)$ of the swabs examined contained Ps. pyocyanea, two of the positives being from an old case with long-standing Ps. pyocyanea infection. A comparison was also made of the proportion of patients from whose lesions Ps. pyocyanea was isolated during the periods May 1, to July 31 , in 1948,1949 , and 1950 . Monthly counts of the cases swabbed and the number of these which yielded Ps. pyocyanea were added together and gave the following results :*

*The differences between the proportion of positives in 1949 and $1950\left(\chi^{2}=8 \cdot 0 ; \mathrm{P}<\cdot 01\right)$ and 1948 and $1950\left(\chi^{2}=4.0 ; \mathrm{P}<\cdot 05\right)$ were both significant.

\begin{tabular}{|c|c|c|c|}
\hline \multirow{2}{*}{ Period } & \multirow{2}{*}{$\begin{array}{c}\text { Cases } \\
\text { Swabbed }\end{array}$} & \multicolumn{2}{|c|}{$\begin{array}{l}\text { Cases Yielding } \\
\text { Ps. pyocyanea }\end{array}$} \\
\hline & & No. & $\begin{array}{l}\text { Per- } \\
\text { centage }\end{array}$ \\
\hline $\begin{array}{ccc}\text { May } 1 \text { to July } & 31,1948 \\
, " & , & 1949 \\
, & , & 1950\end{array}$ & $\begin{array}{r}106 \\
89 \\
76\end{array}$ & $\begin{array}{r}11 \\
14 \\
2\end{array}$ & $\begin{array}{r}10 \cdot 4 \\
15 \cdot 7 \\
2.6\end{array}$ \\
\hline
\end{tabular}

Interpretation of the findings from such an arbitrary group of specimens is, of course, very uncertain. The data quoted are preliminary, and even if further records show a continued reduction in the incidence of Ps. pyocyanea it is still impossible to exclude the influence of other factors (e.g., improvements in ward hygiene and the use of specific chemotherapy in other wards). It does, however, seem likely that contaminated soap solution and cetrimide were responsible for a proportion of the added infections, since these fluids were used as a routine for the cleansing of wounds and of operation sites.

\section{Reasons for the Survival of Ps. pyocyanea in Disinfectant Solutions}

Soap is known to be weak in its disinfectant action against Gram-negative bacilli (McCulloch, 1945). In our studies soap solution inoculated with small amounts of a Ps. pyocyanea broth culture was found still to be contaminated after standing 24 hours at room temperature. Cetrimide, though it has been shown to be peculiarly inactive against Ps. pyocyanea (Williams and others, 1944 ; Harper and Cawston, 1945 ; Hood, 1948), is reported to kill the organism in concentrations considerably lower than 1\% (Davies, 1949). In experimental contamination of aqueous cetrimide solutions with peptone water cultures we found that several strains of $P S$. pyocyanea were killed at concentrations of $0.015 \%$ and above in one hour.

The survival of an organism in an environment which is normally lethal to the species might be due to $(a)$ the presence or development of resistant strains; (b) protection of the organisms or neutralization of the disinfectant by proteins or other organic compounds; and (c) other factors, for example, intermittent contact with the disinfectant.

A few experiments were made with the purpose of finding if one or more of these mechanisms might account for the presence of Ps. pyocyanea in bottles of cetrimide and $10 \%$ "dettol ".

\section{Experiments to Find Resistant Strains}

Experiment 1. - The resistance to cetrimide of two strains of Ps. pyocyanea was estimated, one of the 
strains having been isolated from a stock bottle of $1 \%$ cetrimide and the other having no history of contact with cetrimide. The method used was as follows.

Amounts, each of $0.04 \mathrm{ml}$. 24-hour peptone water cultures of Ps. pyocyanea, were added from a dropping pipette to $0.5 \mathrm{ml}$. amounts of a range of doubling dilutions of cetrimide in distilled water. After standing at room temperature for periods of one hour, six hours, and 24 hours, the tubes were shaken and loopful subcultures to peptone water were made. Peptone water tubes were examined for turbidity after overnight incubation at $37^{\circ} \mathrm{C}$. and subcultured to agar plates for confirmation. After the 24 hours' subculture, the $0.5 \mathrm{ml}$. amounts of cetrimide were diluted with $10 \mathrm{ml}$. "lemco" broth and incubated overnight to detect small numbers of surviving organisms. The results showed no difference in sensitivity to cetrimide of the two strains, the highest concentrations (g. \%) from which Ps. pyocyanea was isolated being as follows:

\begin{tabular}{|c|c|c|c|}
\hline & \multicolumn{3}{|c|}{$\begin{array}{c}\text { Standing Time } \\
\text { (hours) }\end{array}$} \\
\hline & 1 & 6 & 24 \\
\hline $\begin{array}{l}\text { Strain A (no history of contact } \\
\text { with cetrimide) } \\
\begin{array}{c}\text { Strain E.1051 } \\
\text { (from }\end{array} \text { cetrimide } \\
\text { bottle) }\end{array}$ & $\begin{array}{l}0.015 \\
0.015\end{array}$ & $\begin{array}{l}0.007 \\
0.007\end{array}$ & $\begin{array}{l}0.007 \\
0.007\end{array}$ \\
\hline
\end{tabular}

Experiment 2.-Using the same method, the sensitivity to "dettol" of two strains of Ps. pyocyanea isolated from bottles of $10 \%$ "dettol " was compared with the sensitivity of two other strains. The highest concentrations (\%) from which Ps. pyocyanea was isolated were as follows :

\begin{tabular}{|c|c|c|c|}
\hline \multirow{2}{*}{ Strain } & \multicolumn{3}{|c|}{ Standing Time (hours) } \\
\hline & 1 & 6 & 24 \\
\hline 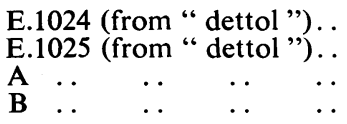 & $\begin{array}{l}12 \cdot 5 \\
12 \cdot 5 \\
12 \cdot 5 \\
6 \cdot 25\end{array}$ & $\begin{array}{l}6 \cdot 25 \\
6 \cdot 25 \\
6 \cdot 25 \\
6 \cdot 25\end{array}$ & $\begin{array}{l}<6.25 \\
<6.25 \\
<6.25 \\
<6.25\end{array}$ \\
\hline
\end{tabular}

Resistant strains or mutants were apparently not responsible for the contamination of the fluids from which the organisms under test were isolated. Moreover, several attempts to induce Ps. pyocyanea to acquire resistance to cetrimide were unsuccessful.

\section{Experiments to Determine Protection by Organic Compounds}

Experiment 3.-Twenty-four hour peptone water cultures of four strains of Ps. pyocyanea were subcultured to a range of doubling dilutions of cetrimide from $10 \%$ to $0.15 \%$ in broth. The strains of $P s$. pyocyanea had not been in contact with cetrimide since their isolation. After incubation for 24 hours at $37^{\circ} \mathrm{C}$. all four strains were found to be growing in all dilutions of cetrimide broth. The experiment was repeated with peptone water solutions of cetrimide, and the results were the same as with broth.

Experiment 4.-Twenty-four hour peptone water cultures of two of the strains used in Experiment 3 were centrifuged and re-suspended in horse serum. Amounts, each of $0.04 \mathrm{ml}$., of these suspensions and of the original peptone water cultures were added by dropping pipette to $0.5 \mathrm{ml}$. amounts of a range of doubling dilutions of cetrimide from $10 \%$ to $0.001 \%$. Subcultures of these suspensions were made as in Experiment 1, and the highest concentrations of cetrimide from which $P s$. pyocyanea could be isolated were as follows :

\begin{tabular}{c|c|c|c|c|c}
\hline Strain & Suspended in & $\begin{array}{c}15 \\
\text { minutes }\end{array}$ & $\begin{array}{c}1 \\
\text { hour }\end{array}$ & $\begin{array}{c}6 \\
\text { hours }\end{array}$ & $\begin{array}{c}24 \\
\text { hours }\end{array}$ \\
\hline A & serum & $\mathbf{0 . 0 3}$ & $\mathbf{0 . 0 1 5}$ & $\mathbf{0 . 0 1 5}$ & $\mathbf{0 . 0 1 5}$ \\
& peptone water & $\mathbf{0 . 0 0 7}$ & $\mathbf{0 . 0 0 7}$ & $\mathbf{0 . 0 0 4}$ & $\mathbf{0 . 0 0 4}$ \\
B & serum & $\mathbf{0 . 1 2 5}$ & $\mathbf{0 . 0 6}$ & $\mathbf{0 . 0 1 5}$ & $\mathbf{0 . 0 1 5}$ \\
& peptone water & $\mathbf{0 . 0 0 7}$ & $\mathbf{0 . 0 0 7}$ & $\mathbf{0 . 0 0 4}$ & $\mathbf{0 . 0 0 4}$ \\
\hline
\end{tabular}

Experiment 5.-Experiment 1 was repeated, using $1 \%$ cetrimide solution taken from a bottle in which Ps. pyocyanea had been found and at the same time a freshly-made cetrimide solution.

The highest concentrations of both solutions from which $P$ s. pyocyanea could be cultured were 0.015 after one hour and $0.007^{\circ}$ after six hours. Since there was no difference in the disinfectant power of the two solutions, survival of Ps. pyocyanea in the cetrimide bottle had obviously not been due to substances in the solution itself.

From these experiments it may be inferred that organic substances in solution with cetrimide can neutralize its disinfectant action against strains of $P s$. pyocyanea and that there is a degree of protection of these strains by serum added with the organism to aqueous cetrimide solution. The cetrimide solution in a contaminated stock bottle, however, does not contain enough of such solutes to protect added Ps. pyocyanea.

\section{Artificial Contamination of a Cetrimide Bottle}

Growth of Ps. pyocyanea from a culture plate was spread on the inside of a cork covering a bottle of $1 \%$ cetrimide. During the first six hours the bottle was inverted about once every hour. Swabs taken from the cork one hour, three hours, six hours, and 24 hours after inoculation were heavily contaminated with $P s$. pyocyanea and swabs from the fluid were positive one hour, three hours, and six hours after the cork had been inoculated.

\section{Discussion}

The isolation of $P s$. pyocyanea from fluids applied to wounds has revealed a preventable reservoir of wound infection which may be common and is of particular importance in the infection of adequately covered wounds. Measures to ensure and maintain the sterility of certain fluids, including such disinfectants as cetrimide and 10\% "dettol" 
are necessary and have been achieved by dispensing them in autoclaved screw-cap bottles. Since the introduction of such sterile fluids the incidence of wound infection with Ps. pyocyanea has fallen.

The question arises why Ps. pyocyanea and other organisms survive in disinfectant fluids at concentrations which are lethal to these organisms in distilled water in a test tube. Strains of Ps. pyocyanea isolated from cetrimide and "dettol" were no more resistant to these disinfectants than other strains. The fact that Ps. pyocyanea will readily grow in culture media containing $1 \%$ and more of cetrimide suggests a mechanism by which organisms deposited on the corks of bottles may survive intermittent contact with this fluid. This explanation gains support from the observation of Nelson (1942), who isolated coliform bacilli from bottles of sterile distilled water, and showed that growth-promoting substances could be derived from cork. Deposited on moistened corks by contaminated fingers, Ps. pyocyanea might be expected to survive in bottles of cetrimide and "dettol" at a concentration which kills the organism when it is unprotected. An envelope of dried exudate from the wound in which the contaminating organism had previously grown would contribute further protection. The organisms probably persist on the cork, from which they are periodically washed into the fluid when the bottle is tipped up or inverted. Special stress is therefore laid on the disadvantages of corks which not only fail to protect the rim of the bottle neck from contamination but also provide a nidus on which bacteria persist and may even multiply. The replacement of large corked bottles by small screwcap bottles should be attainable in all industrial medical departments.

Other precautions are desirable wherever possible. The bottles should be sterilized before, or preferably after, filling with the fluid. In industrial medical departments where facilities for autoclaving are not available, it would be reasonable to boil screwcap bottles of cetrimide, soap solution, and $10 \%$ "dettol" in the sterilizer. Such a simple daily routine using water starting up from cold should be neither time-consuming nor cause too great a loss from cracked bottles.

\section{Summary}

Ps. pyocyanea was isolated from bottles of $1 \%$ cetrimide solution, $2 \%$ soap solution, $10 \%$ " dettol ", and calamine lotion used in hospital dressing stations and operating theatres. The contaminated fluids were in bottles with corks.

Fluids dispensed in small sterile screw-cap bottles were found to be free from contamination by Ps. pyocyanea and there was evidence of a reduction in the rate of infection of wounds by the organism after the new method of dispensing was introduced.

The survival of bacteria in solutions of disinfectant is briefly discussed.

Special care is recommended in the dispensing of such fluids for hospitals and industrial medical departments. Small screw-cap bottles should be used, when possible filling the bottles before they are autoclaved or boiled.

I am indebted to $\mathrm{Mr}$. W. Recht for suggestions which encouraged me to undertake this study. I also wish to thank Dr. S. Sevitt for permission to use his clinical pathology records, and Mr. H. Lilly for technical assistance.

\section{REFERENCES}

Clayton-Cooper, B., and Williams, R. E. O. (1945). British Journal of Industrial Medicine, 2, 146.

Davies, G. E. (1949). J. Hyg. Camb., 47, 271.

Harper, G. J., and Cawston, W. C. (1945). Bull. Inst. med. Lab. Techn., 11, 40.

Hood, A. M.'(1948). Mon. Bull. Min. Hlth., 7, 248.

Lowbury, E. J. (195i). In the press.

McCulloch, E. C. (1945). Disinfection and Sterilization 2nd ed.,

McCulloch, 354 . London.
pedical Research Council (1941). “The Prevention of 'Hospital Infection' of Wounds ". War Memo. No. 6.

Nelson, J. H. (1942). J. Path. Bact., 54, 449.

Williams, R. E. O., Clayton-Cooper, B., Faulkner, H. C., and Thomas, H. E. (1944). Lancet, 1, 787. 